\title{
Risk Prediction of the Diabetes Missing Million: Identifying Individuals at High Risk of Diabetes and Related Complications
}

\author{
Marc Evans - Angharad R. Morgan - Dipesh Patel · Ketan Dhatariya • \\ Sharlene Greenwood • Philip Newland-Jones • Debbie Hicks • \\ Zaheer Yousef · Jim Moore · Bethany Kelly · Sarah Davies · \\ Umesh Dashora
}

Received: October 14, 2020 / Accepted: October 28, 2020 / Published online: November 14, 2020

(C) The Author(s) 2020

\section{ABSTRACT}

Early diagnosis and effective management of type 2 diabetes (T2D) are crucial in reducing the risk of developing life-changing complications such as heart failure, stroke, kidney disease, blindness and amputation, which are also associated with significant costs for healthcare providers. However, as T2D symptoms often develop slowly it is not uncommon for people

\section{Evans $(\bowtie)$}

Diabetes Resource Centre, University Hospital Llandough, Cardiff, UK

e-mail: marclyndon1@hotmail.com

\section{A. R. Morgan}

Health Economics and Outcomes Research Ltd., Cardiff, UK

\section{Patel}

Department of Diabetes, Division of Medicine, University College London, Royal Free NHS Trust, London, UK

\section{K. Dhatariya}

Elsie Bertram Diabetes Centre, Norfolk and Norwich University Hospitals NHS Foundation Trust,

Norwich, UK

\section{S. Greenwood}

Renal Medicine, King's College Hospital, London, UK

S. Greenwood

Renal Sciences, Faculty of Life Sciences and Medicine, King's College London, London, UK to live with T2D for years without being aware of their condition-commonly known as the undiagnosed missing million. By the time a diagnosis is received, many individuals will have already developed serious complications. While the existence of undiagnosed diabetes has long been recognised, wide-reaching awareness among the general public, clinicians and policymakers is lacking, and there is uncertainty in how best to identify high-risk individuals. In this article we have used consensus expert opinion alongside the available

P. Newland-Jones

University Hospitals Southampton NHS Foundation

Trust, Southampton, UK

D. Hicks

Medicus Health Partners, Enfield, London, UK

Z. Yousef

Wales Heart Research Institute, Cardiff University, Cardiff, UK

J. Moore

Stoke Road Surgery, Bishop's Cleeve, Cheltenham, UK

B. Kelly

Solent NHS Trust, Southampton, UK

S. Davies

Woodlands Medical Centre, Cardiff, UK

U. Dashora

East Sussex Healthcare NHS Trust, St Leonards-onSea, UK 
evidence, to provide support for the diabetes healthcare community regarding risk prediction of the missing million. Its purpose is to provide awareness of the risk factors for identifying individuals at high, moderate and low risk of T2D and T2D-related complications. The awareness of risk predictors, particularly in primary care, is important, so that appropriate steps can be taken to reduce the clinical and economic burden of T2D and its complications.

Keywords: Chronic kidney disease; Diabetesrelated complications; Heart failure; Risk prediction; Type 2 diabetes

\section{Key Summary Points}

In the UK it is estimated that up to one million people have undiagnosed or unrecorded diabetes and are not receiving access to regular health checkscommonly referred to as 'the missing million'.

By the time a diagnosis is received, many individuals will have already developed serious diabetes complications.

While the existence of undiagnosed diabetes has long been recognised, widereaching awareness of the risk factors is lacking, and there is uncertainty in how best to identify high-risk individuals.

In this article, expert consensus advice is presented in order to provide awareness of the risk factors for undiagnosed diabetes and diabetes-related complications summarised in a simple traffic light system.

The aim of the article is to aid in identifying people at high, moderate and low at risk of incident diabetes and diabetes-related complications, with the goal of improving the lives of people with diabetes.

\section{DIGITAL FEATURES}

This article is published with digital features to facilitate understanding of the article. You can access the digital features on the article's associated Figshare page. To view digital features for this article go to https://doi.org/10.6084/m9. figshare.13148096.

\section{INTRODUCTION}

Globally, it is estimated that just under a half a billion people are living with diabetes, which is approximately 1 in 11 of the world's adult population [1]. As many as $45.8 \%$ of adult diabetes cases are thought to be undiagnosed [2], which may be attributable to a variety of factors including underperforming health systems, the prolonged asymptomatic phase between the onset of hyperglycaemia and diagnosis, and in particular low awareness among the general public and health professionals. In the UK it is estimated that up to one million people are living with undiagnosed diabetes-commonly referred to as 'the missing million' [3]. The majority of these will have type 2 diabetes (T2D), although there may be a small proportion with type 1 diabetes (T1D). A recent study of approximately 200,000 individuals from the UK Biobank reported that $1.1 \%$ had undiagnosed diabetes, with a glycated haemoglobin (HbA1c) measurement of $48 \mathrm{mmol} / \mathrm{mol}(6.5 \%)$ or higher, 2 years before receiving a clinical diagnosis [4]. This study is likely to have underestimated the true prevalence of undiagnosed diabetes as the Biobank population is not considered representative of the general population because of a healthy volunteer selection bias [5].

Type 1 diabetes (T1D) is characterised by insulin deficiency as a consequence of the destruction of pancreatic beta cells, due to autoimmunity (type 1A, including latent autoimmune diabetes of adults whereby insulin production is lost at a slower rate) or a strong hereditary component, with no evidence of autoimmunity (type $1 \mathrm{~B}$ or idiopathic diabetes). Type 2 diabetes (T2D) is characterised by insulin resistance and/or abnormal insulin secretion 
and increased glucose production. Before people develop T2D they almost always have prediabetes whereby blood glucose levels are higher than normal, but not yet high enough for a diagnosis of T2D. All forms of diabetes are defined by chronic hyperglycaemia which can lead to the subsequent development of diabetes-related micro- and macrovascular complications such as kidney disease, retinopathy, neuropathy, cardiovascular disease (CVD), stroke and peripheral artery disease (PAD). Timely interventions can reduce hyperglycaemia and the risk of complications in people diagnosed with diabetes [6-14], but this potential opportunity is missed in those who remain undiagnosed [15]. Indeed, by the time a diagnosis is received, $20-30 \%$ of individuals will have already developed serious complications [16]. Furthermore, undiagnosed diabetes is reported to carry a similar risk of mortality to diagnosed diabetes and has been associated with a 1.5- to 3.0-fold higher risk of mortality compared to individuals without diabetes $[17,18]$

As a large proportion of the total cost of diabetes is associated with the management of complications the economic burden of undiagnosed diabetes is likely to be significant. A total cost of $£ 39.8$ billion has been projected for diabetes expenditure in the UK by $2035 / 2036$ (approximately $17 \%$ of the NHS budget), consisting of $£ 16.9$ billion in direct costs and $£ 22.9$ billion in indirect costs [19].

Although primary care is considered essential for the management of diabetes there are often limited resources to support effective diabetes screening. Furthermore, for healthcare professionals working in primary care, recognising risk factors for diabetes may be challenging because of conflicting guidance. A survey around the knowledge of screening for, diagnosing and managing prediabetes in 140 primary care providers, including physicians, nurse practitioners and physician assistants, identified important gaps in primary care practitioners' knowledge of risk factors that should prompt screening [20]. This clinical inertia is manifested by a delay in a timely diagnosis and therapy initiation. As such, there is an unmet need for education strategies around diabetes risk prediction for healthcare professionals to more readily identify high-risk individuals. In particular, diabetes prevention programmes may be more cost-effective if they are directed to those at highest risk [21].

The objective of this consensus review is to raise awareness of the key risk factors that healthcare professionals should familiarise themselves with, so as to be able to identify individuals at high, moderate and low risk of undiagnosed diabetes in primary care and in the community. Early identification of undiagnosed diabetes may delay or prevent disease progression through the timely introduction of preventive strategies such as behavioural change programmes or medication. The review focuses on T2D and does not include T1D. However, as a large proportion of people diagnosed with T1D have ketoacidosis, with incidence varying in different populations from $13 \%$ to $80 \%$ [22], recognising the main symptoms of T1D can help to get a diagnosis before ketoacidosis develops. Some of the most noticeable and common symptoms include excessive thirst, unusually high levels of urination, tiredness, loss of muscular bulk and unexplained weight loss. Other symptoms include recurring thrush, blurred vision, unexpected cramping, and skin infections. Factors, beyond symptoms, which might point to a diagnosis of T1D include family and prior history of autoimmune disease and family history of T1D.

Moving beyond the development of simple risk stratification for incident $\mathrm{T} 2 \mathrm{D}$, set in the context of a growing awareness of both clinical and economic disease burden we extend our consensus review to include an approach to the identification and thus timely management of those at risk of two particularly prevalent and costly complications associated with diabetes, namely chronic kidney disease (CKD) and heart failure (HF). The ultimate aim of this document is, through the provision of a simple risk grading mechanism (developed on the basis of consensus opinion), to raise awareness of those who remain unidentified with potentially lifechanging conditions, with the ultimate goal of improving the lives of people with diabetes. 
This article is based on previously conducted studies and does not contain any studies with human participants or animals performed by any of the authors.

\section{IDENTIFYING UNDIAGNOSED T2D}

In the UK, the National Institute of Health and Care Excellence (NICE) recommends a twostage strategy to identify people at high risk of T2D. In the first instance this includes the offer of a risk assessment, followed by, where necessary, a blood test to confirm whether people have T2D or are at high risk [21]. The guidelines suggest that a risk assessment should be offered to eligible adults aged 40 and above (except pregnant women), people aged 25-39 of South Asian, Chinese, African-Caribbean, black African and other high-risk black and minority ethnic groups (except pregnant women), and adults with conditions that increase the risk of T2D, e.g. CVD, hypertension, obesity, stroke, polycystic ovary syndrome, a history of gestational diabetes and mental health problems [21].

Various diabetes risk assessment tools have been developed in numerous populations, either for self-assessment or to be completed by a healthcare professional. Using a variety of risk factors, weighting schemes and thresholds such risk scores aim to identify those at risk for future T2D. Although the risk assessments each have several key risk factors in common, they also include additional different risk predictors. Table 1 provides an overview of the key risk factor assessment tools developed using Western populations.

Despite the availability of several algorithms for predicting diabetes risk, most have shown limited screening accuracy with low positive predictive value, they often lack user convenience and the different risk assessments predict dissimilar numbers at 'high risk' [23]. Although several risk scores have been validated in independent populations, with many showing good discriminatory ability, discrimination is generally lower than in the populations in which the scores were developed, and the validation results are more heterogeneous [24]. As such most of risk scores are unlikely to be generalisable from one population to another in a different country.

As a result of the lack of a universal standard tool that can be used internationally, it may be more appropriate to focus on isolated risk factors that place individuals at high, moderate or low risk of having undiagnosed diabetes. To this end, we have summarised in a simple traffic light checklist the key risk factors that we as a consensus expert group consider important for identifying at risk individuals. The objective of the checklist is to highlight to non-specialists factors that can identify people at high, moderate and low risk of incident T2D (Fig. 1).

\section{Risk Factors Associated with High Risk of T2D}

Prediabetes, characterised by impaired fasting glucose (defined as fasting plasma glucose of 6.1-6.9 mmol/L $(110-124 \mathrm{mg} / \mathrm{dL})$, in the absence of impaired glucose tolerance) [25] and/ or impaired glucose tolerance (defined as postload plasma glucose of $7.8-11.0 \mathrm{mmol} / \mathrm{L}$ (140-198 mg/dL) based on 2-h oral glucose tolerance test [25]), is a key risk factor for developing T2D. It does not always lead to T2D, but between $33 \%$ and $66 \%$ of people with prediabetes will go on to develop T2D over a period of 3-6 years [26-29]. As well as predisposing individuals to a high probability of progression to $\mathrm{T} 2 \mathrm{D}$, individuals with prediabetes are at increased risk of developing many of the complications associated with T2D, such as CVD, $\mathrm{HF}, \mathrm{CKD}$, diabetic retinopathy and neuropathy, and also have increased risk of all-cause mortality [30, 31]. The risk factors for prediabetes are largely the same as those for T2D, and therefore healthcare professionals should be aware of these risk factors in order to consider screening for T2D or prediabetes in individuals deemed to be 'high risk'.

Gestational diabetes is a glucose intolerance with onset or first diagnosis during the second or third trimester of pregnancy, which is clearly not either pre-existing T1D or T2D [32], and predisposes women to a high risk for developing later T2D [33]. In a recent meta-analysis of 20 


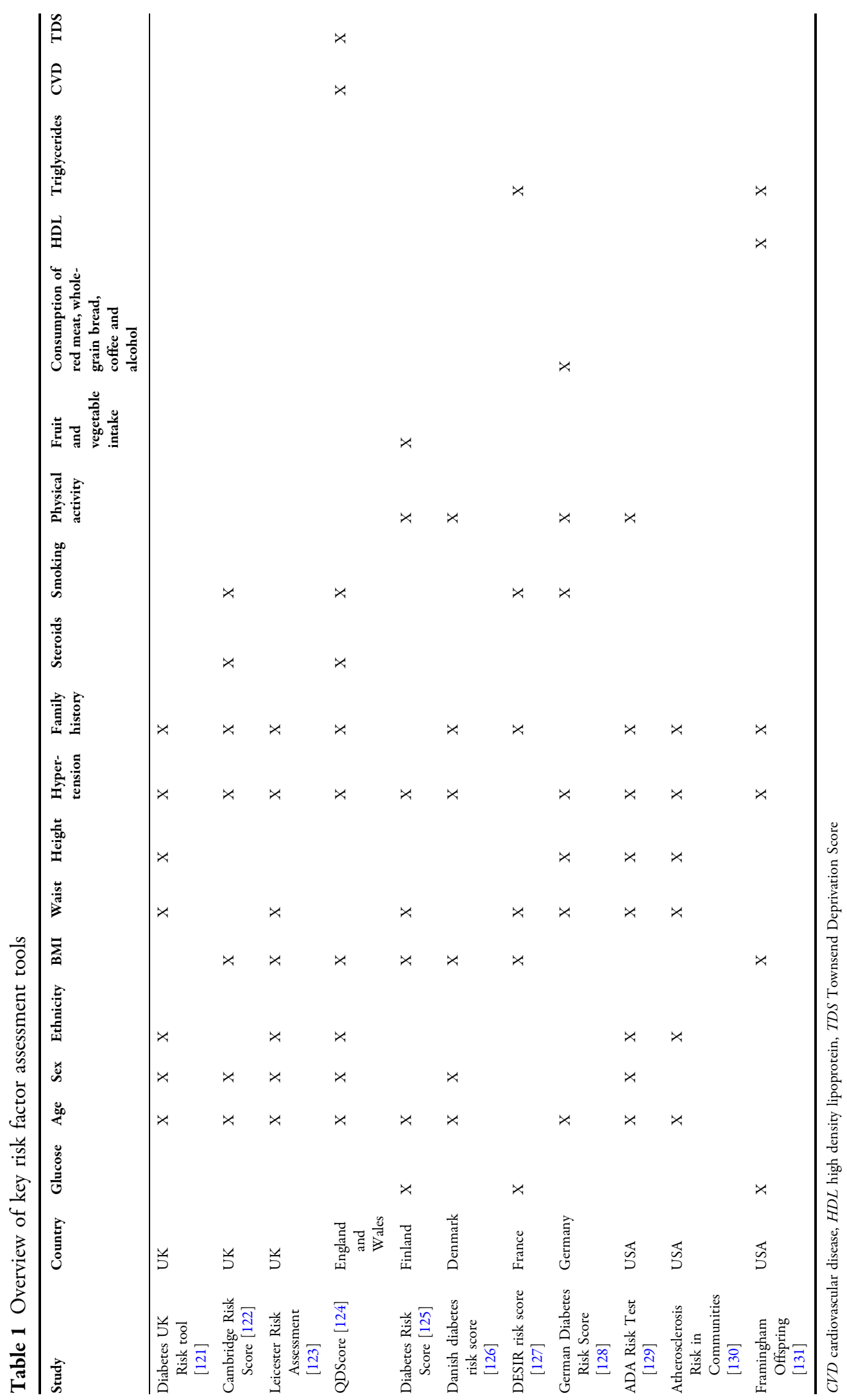




\begin{tabular}{|l|l|}
\hline & High risk \\
\hline Prediabetes \\
History of gestational diabetes \\
Long term (more than 3 courses in a year) steroid use at a daily dose of $\geq 5 \mathrm{mg}$ \\
Pre-existing CVD \\
Black, Asian or minority ethnic group \\
Obesity (BMI $\geq 30$ ) \\
BMI $>27$ in Asians \\
Waist circumference $>88 \mathrm{~cm}$ (males $/>80 \mathrm{~cm}$ females) \\
Moderate risk \\
\hline $\begin{array}{l}\text { Physical inactivity } \\
\text { Energy-dense Western style diet } \\
\text { Smoking } \\
\text { Family history of T2D } \\
\text { Hypertension } \\
\text { Polycystic ovary syndrome } \\
\text { Non-alcoholic fatty liver disease } \\
\text { Low socioeconomic status } \\
\text { Age }>45 \text { years } \\
\text { Low risk }\end{array}$ \\
\hline \begin{tabular}{l} 
Age $<45$ years, with absence of any of the above \\
\hline
\end{tabular} \\
\hline
\end{tabular}

Fig. 1 Risk factors for identifying undiagnosed T2D. BMI body mass index, CVD cardiovascular disease, T2D type 2 diabetes

studies that included a total of 1,332,373 individuals, women with a history of gestational diabetes had approximately a tenfold higher risk of developing T2D than those with a normoglycemic pregnancy [34]. As a result of the magnitude of the risk, regular postpartum screening would be a valuable strategy to identify those at risk of progression to T2D.

Although glucocorticoids are widely prescribed for their anti-inflammatory and immunosuppressive properties to help with the management of pulmonary diseases, autoimmune conditions, neurologic diseases and inflammatory bowel diseases, glucocorticoids have a powerful impact on glucose metabolism, contributing to hyperglycaemia and placing individuals at high risk of T2D [35]. A recent meta-analysis of studies evaluating the occurrence of hyperglycaemia in individuals without diabetes treated with steroids found that the rates of steroid-induced hyperglycaemia and steroid-induced diabetes were $32.3 \%$ and $18.6 \%$, respectively [36]. The length of time on steroids as well as the relative potency and the absolute dose all play a role in the occurrence of steroid-induced diabetes $[37,38]$. Strategies are needed to detect those at high risk for developing steroid-induced diabetes so that they can receive blood glucose monitoring whilst undergoing steroid therapy. On the basis of consensus exert opinion we advise that people receiving long-term (more than three courses in a year) prednisolone at a daily dose of $5 \mathrm{mg}$ or more are at high risk of incident T2D.

Pre-existing CVD is a strong predictor of T2D, with $25-36 \%$ of people with CVD developing T2D as a non-cardiovascular comorbid condition [39]. This may be explained by the fact that T2D shares risk factors with CVD such as insulin resistance, dyslipidaemia, abdominal obesity, smoking and physical inactivity.

Ethnicity is a well-established risk factor for the development of T2D, with prevalence being considerably higher among Black, Asian and minority ethnic (BAME) groups compared to White populations [40-43]. In a cross-sectional analysis investigating ethnic differences in the prevalence of T2D in the UK, the likelihood of 
having T2D was more than double among the Asian ethnic group compared with the White ethnic group, and increased by $65 \%$ among the Black group and by $17 \%$ among the Mixed/ Other group [44]. In addition, it has also been demonstrated that people of Black and South Asian ethnicity develop T2D approximately 10 years earlier age than people from White populations [45], and South Asians are also diagnosed at lower BMI, younger age and with rapid progression of diabetic complications compared with other ethnic groups [46].

Obesity is one of the biggest risk factors for T2D, accounting for $80-85 \%$ of the overall risk of developing the condition [47]. Compared with people of normal weight (BMI $<25 \mathrm{~kg}$ / $\left.\mathrm{m}^{2}\right)$, those with obesity $\left(\geq 30 \mathrm{~kg} / \mathrm{m}^{2}\right)$ are almost six times more likely to develop T2D, while people who are overweight ( $\geq 25$ to $<30 \mathrm{~kg}$ / $\mathrm{m}^{2}$ ) have 2.4 times increased risk [48]. The effect of obesity on T2D risk has been demonstrated to be dominant over other risk factors [48]. In addition to the degree of obesity, the location of the excess body fat is also important in determining the risk of $\mathrm{T} 2 \mathrm{D}$, with the risk being highest in a people who carry the majority of their excess body weight around their abdomen. In a study examining waist circumference it was found that men with a waist circumference of 94-102 cm were at increased risk of T2D, and the risk was increased further if waist circumference was more than $102 \mathrm{~cm}$. Women were at high risk if they had a waist circumference of $80-88 \mathrm{~cm}$ and at very high risk if it was more than $88 \mathrm{~cm} \mathrm{[49].}$

Considering the significant risk associated with each of these factors discussed above, our consensus opinion is that the presence of one or more of these factors should act as an indication to evaluate an individual for the presence of undiagnosed diabetes.

\section{Risk Factors Associated with Moderate Risk of T2D}

Lifestyle-related risk factors, such as physical inactivity and an energy-dense Western style diet, contribute to obesity [50] and further increase the risk of T2D [51]. In addition, smoking has also been shown to increase the risk of T2D, with the larger the number of cigarettes smoked and the earlier a person started smoking increasing this risk [52-54].

A family history of T2D increases a person's risk of developing T2D themselves. The estimated risk for T2D increases by two to four times if a parent has T2D [55]. It is likely that this elevated risk of T2D is mediated, in part, by both genetic and shared environmental components amongst family members, but the precise factors accounting for this increase in risk are poorly understood.

Hypertension is another risk factor for T2D because of its association with insulin resistance. In an analysis of 4.1 million individuals in a UK primary care population, raised systolic blood pressure of $20 \mathrm{mmHg}$ increased the risk of T2D by $58 \%$ and a raised diastolic blood pressure of $10 \mathrm{mmHg}$ was associated with a $52 \%$ higher risk of T2D. The findings were confirmed by the results of a meta-analysis of existing prospective studies, which demonstrated a $77 \%$ increased risk of T2D for a $20 \mathrm{mmHg}$ higher than average systolic blood pressure [56].

Polycystic ovary syndrome (PCOS) is an incurable endocrine condition associated with irregular ovulation, biochemical/clinical hyperandrogenism and/or polycystic ovaries that affects up to one in ten women in the UK $[57,58]$. Women who have PCOS have a four times higher risk of developing T2D, compared to women without PCOS, and are also often diagnosed at an earlier age $[59,60]$.

Non-alcohol related fatty liver disease (NAFLD), defined as the presence of at least 5\% hepatic fat accumulation in patients who do not consume excessive alcohol consumption (less than $20 \mathrm{~g} /$ day for women and less than $30 \mathrm{~g} /$ day for men) and in the absence of other recognised causes of fatty liver, e.g. virus, drugs, autoimmunity [61-63], is common in people with T2D, with a prevalence of 55-68\% [64]. A meta-analysis of 19 observational studies with 296,439 individuals $(30.1 \%$ with NAFLD) demonstrated that NAFLD was associated with a twofold increased risk of incident diabetes [65]. It remains uncertain whether NAFLD causally increases diabetes risk or is a consequence of 
shared multiple cardiometabolic risk factors between the two conditions.

Data from the National Diabetes Audit indicates that people in the most deprived quintile are 1.5 times more likely to have diabetes than those in the least deprived [66]. Low socioeconomic status is strongly associated with higher levels of obesity, physical inactivity, unhealthy diet, smoking and poor blood pressure control. As described above all these factors are established predictors of T2D.

On the basis of the above discussion, our consensus view is that the presence of two or more of these parameters should act as an alert to the need to evaluate an individual for the presence of undiagnosed diabetes.

Risk Factors Associated with Low Risk of T2D Age is an important risk factor for T2D with the burden of the disease increasing with age, especially after 45 years, as a result of insulin resistance increasing and pancreas function decreasing. In addition, people tend to exercise less, lose muscle mass and gain weight as they age, which all are additional risk factors for T2D. The strong association of diabetes with age is of particular concern given the global ageing of the population. However, it should be noted that in recent years T2D has been occurring with increasing frequency in younger individuals. We advise that individuals aged 45 years or older, with absence of any of the above risk factors, may be considered at low risk of T2D.

\section{IDENTIFYING RISK OF HF IN DIAGNOSED T2D}

People with T2D are at increased risk for developing CVD, including myocardial infarction, stroke, coronary artery disease (CAD), PAD and HF. T2D is associated with an up to fivefold increase in the risk of $\mathrm{HF}[67,68]$, and whilst the prevalence of T2D in the general population is approximately $10-15 \%$, approximately $40 \%$ of patients hospitalised with HF also have T2D [69]. Furthermore, the development of HF in people with $\mathrm{T} 2 \mathrm{D}$ has been associated with a four- to tenfold increase in mortality risk $[70,71]$.
There is a need to increase awareness around $\mathrm{HF}$ in primary care, as it is evident that HF diagnosis is being delayed or indeed not happening despite patients presenting with relevant symptoms. As a result, the majority of $\mathrm{HF}$ diagnoses are made in hospital, often acutely, following which the prognosis is poorer.

Estimates of HF risk can be useful for both clinicians and people with T2D: for clinicians, it can support them in the choice of therapeutic and preventive strategies; and for individuals with T2D, it can be a motivation tool to adopt healthy lifestyle measures and to observe prescribed risk-modifying treatments. Risk scores for HF in T2D include the WATCH-DM (Weight [BMI], Age, hyperTension, Creatinine, HDL-C, Diabetes control [fasting plasma glucose], QRS Duration, MI and CABG) score which is a simple, user-friendly, integer-based risk score that calculates the 5-year risk of incident HF among people with T2D [72], the TIMI (Thrombolysis in Myocardial Infarction) Risk Score for Heart Failure in Diabetes (TRS-HFDM) which is a novel, integer-based clinical risk score for predicting hospitalization for $\mathrm{HF}$ in people with T2D that includes the risk predictors prior HF, history of atrial fibrillation (AF), CAD, estimated glomerular filtration rate (eGFR) and urine albumin-to-creatinine ratio [73], and the Brest score which is a clinical prediction score for HF diagnosis in the emergency care setting that includes 11 variables: age at least 65 years, seizure dyspnoea, night outbreak, orthopnoea, history of pulmonary oedema, chronic pulmonary disease, myocardial infarction, crackles, leg oedema, ST segment abnormality, atrial fibrillation/flutter on electrocardiography [74].

As HF is one of the most common as well as earliest presenting CV complications of T2D, there is a need for the inclusion of questions related to HF in routine T2D checks in primary care. Healthcare practitioners involved in chronic disease clinics in primary care typically use disease-specific templates to record information. However, practitioners should also consider the addition of questions around changes in exercise tolerance (breathlessness on exertion), orthopnoea/paroxysmal nocturnal dyspnoea and ankle swelling to the existing practice diabetes templates. Where clinical 


\begin{tabular}{|l|l|}
\hline & High risk \\
\hline Bistory of CVD (in particular prior MI) \\
$\begin{array}{l}\text { Abnormal ECG } \\
\text { Long duration of T2D (> 10 years) } \\
\text { History of CKD } \\
\text { Albuminuria } \\
\text { Peripheral oedema }\end{array}$ \\
$\begin{array}{l}\text { Moderate risk } \\
\text { Obesity (BMI } \geq 30) \\
\text { Hypertension } \\
\text { Smoking } \\
\text { Short duration T2D (<5 years) } \\
\text { Low risk }\end{array}$ \\
\hline $\begin{array}{l}\text { No CVD } \\
\text { Normal ECG } \\
\text { No symptoms e.g. shortness of breath, lethargy, ankle oedema } \\
\text { Non smoker } \\
\text { Normotensive }\end{array}$ \\
\hline
\end{tabular}

Fig. 2 Risk factors for identifying HF. BMI body mass index, CKD chronic kidney disease, CVD cardiovascular disease, ECG echocardiogram, T2D type 2 diabetes

features suggest a possible diagnosis of $\mathrm{HF}$, an assessment of natriuretic peptides (brain natriuretic peptide (BNP) or N-terminal pro-BNP) should be undertaken in the first instance and those with a raised level referred urgently for assessment. The clinical features that place individuals with T2D at high, moderate or low risk of HF diabetes are discussed below and summarised in Fig. 2.

\section{Risk Factors Associated with High Risk of HF in T2D}

Breathlessness on exertion is a typical symptom of HF [75]. Breathlessness is also common in patients with obesity, and patients with obesity $\left(\geq 30 \mathrm{~kg} / \mathrm{m}^{2}\right)$ are approximately six times more likely to develop T2D [47]. Therefore, whilst breathlessness in patients with T2D may be unrelated to $\mathrm{HF}$, any undue breathlessness or change in exercise tolerance should be investigated.

The presence of other CVD such as CAD, prior $\mathrm{MI}, \mathrm{AF}$ and hypertension are all risk factors for the development of HF [76]. In patients with diabetes hospitalised with $\mathrm{HF}$, the majority exhibit other CV comorbidities such as ischemic heart disease, $\mathrm{AF}$ and hypertension
[77], highlighting the common pathological processes involved in the development of CVD and T2D. As NICE HF guidelines suggest prior $\mathrm{MI}$ is a very high risk factor for HF [78], individuals presenting with symptoms of dyspnoea that have prior MI should be immediately referred for HF assessment.

Patients with abnormal electrocardiogram (ECG) activity are at increased risk of HF. A study that tracked the development of HF in participants following a baseline 12-lead ECG identified the following ECG markers to be significantly associated with the future development of HF: higher resting heart rate, prolonged QRS duration, prolonged initial ventricular depolarization, left-axis deviation, abnormal QRS-T angle, left ventricular hypertrophy, ST/T wave abnormalities and left bundle-branch block [79].

Patients who have had T2D for more than 10 years are at increased risk of HF. Patients with early-onset T2D have approximately two times the risk of non-fatal CVD compared with patients with late-onset T2D at the same age [80], likely because of the longer exposure to the poor glycaemic control, oxidative stress and low-grade inflammation associated with T2D. 
Approximately $40-50 \%$ of patients with HF also have CKD [81]. Furthermore, in patients with T2D, the risk of HF increases with CKD progression, such that patients with eGFR $<30 \mathrm{~mL} / \mathrm{min} / 1.73 \mathrm{~m}^{2}$ have an approximately three times increased risk of developing HF compared to patients with eGFR $\geq 90 \mathrm{~mL} /$ $\min / 1.73 \mathrm{~m}^{2}$ [82].

Albuminuria is prevalent in approximately $30 \%$ of patients with T2D and is a risk factor for CVD $[83,84]$. In patients with T2D, the presence of microalbuminuria increases the risk of hospitalisation for HF by 3.5-fold [84].

Peripheral oedema, particularly swelling of the ankles, and especially if new onset or worsening, is a common symptom of HF [75]. Given the association between HF and T2D, peripheral oedema should be investigated further if present to determine if HF is the cause. As peripheral oedema can develop from multiple causes, difficulty in recognizing the cause may lead to an inappropriate therapeutic approach. The differential diagnosis of peripheral oedema should include observations around skin colour, skin temperature, mono- or bilaterality localization, the presence of the sign of pitting, the presence of the Stemmer sign, the sense of progression of the oedema along the limb and the date of onset of oedema. Following history and physical examination, if HF is suspected as the cause of the oedema we recommend that the individual by immediately referred for HF assessment.

Our consensus view based on the above discussion is that the presence of one or more of these factors should alert to the presence of undiagnosed HF.

\section{Risk Factors Associated with Moderate Risk of HF in T2D}

Obesity is associated with an increased risk of $\mathrm{HF}$, independent of T2D [85]. Every $1 \mathrm{~kg} / \mathrm{m}^{2}$ increase in BMI is associated with an $11 \%$ increase in the risk of HF, meaning that patients who are overweight have an approximately 50\% increase in the risk of $\mathrm{HF}$, and those that are obese have an approximately $180 \%$ increase in HF risk [86].
Longer-term hypertension and increased afterload leads to left-ventricular hypertrophy and diastolic dysfunction, eventually resulting in HF [87]. A cross-sectional study of patients with newly diagnosed T2D in the UK found hypertension (at least $160 \mathrm{mmHg}$ systolic and/ or at least $90 \mathrm{mmHg}$ diastolic or taking antihypertensive therapy) was prevalent in $35 \%$ of male and $46 \%$ of female patients [88]. Whilst the prevalence of hypertension in patients with T2D is relatively high, hypertension is one of the most modifiable risk factors for the development of HF.

Current and former smokers have an increased risk of developing HF than individuals who have never smoked. Compared with people who have never smoked, current smokers are $60-75 \%$ more likely to develop HF, and former smokers are approximately $20 \%$ more likely to develop HF [89, 90]. In former smokers, risk declines over time, with a risk of HF similar to never smokers after 30 years of cessation [89].

The longer a patient with T2D is exposed to the poor glycaemic control, oxidative stress and low-grade inflammation associated with T2D, the greater their risk of developing HF. Whilst T2D itself is associated with up to a fivefold increase in the risk of $\operatorname{HF}[67,68]$, the risk increases alongside diabetes duration, such that patients with early-onset T2D have twice the risk of non-fatal CVD compared with patients with later-onset T2D at the same age [80] and patients with a more recent diagnosis of T2D (e.g. less than 5 years) are at lower risk of developing $\mathrm{HF}$ than patients with a longer duration of T2D (e.g. more than 10 years), although moderate risk remains.

On the basis of the discussion above, our consensus opinion is that the presence of two or more of the factors discussed should alert to the presence of undiagnosed HF.

\section{Risk Factors Associated with Low Risk of $\mathrm{HF}$ in T2D}

The presence of $\mathrm{T} 2 \mathrm{D}$ alone raises the risk of developing HF. Therefore, patients with T2D, without other CVD, normal ECG activity, free of symptoms of HF (such as shortness of breath, 


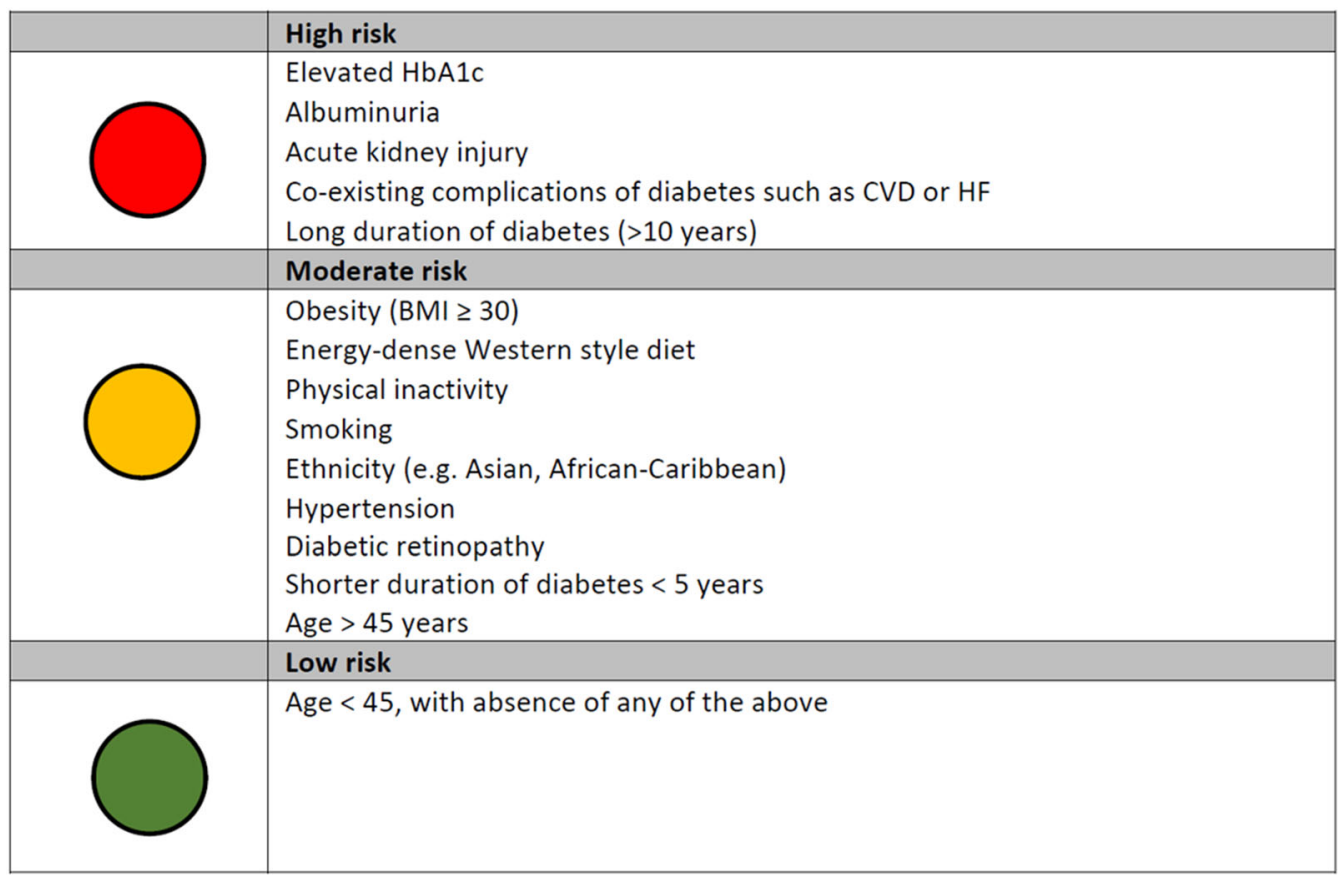

Fig. 3 Risk factors for identifying CKD. BMI body mass index, CVD cardiovascular disease, ECG echocardiogram, HF heart failure

lethargy and ankle oedema), who have never smoked and are normotensive, remain at elevated risk of developing HF despite the absence of other risk factors that-when compoundedincrease risk further.

\section{IDENTIFYING RISK OF CKD IN DIAGNOSED T2D}

CKD is an increasingly prevalent condition associated with an increase in morbidity and mortality and a significant cost burden, and is one of the most common complications of T2D affecting approximately $40 \%$ of people with T2D [91, 92]. It can have a huge impact on the quality of life for people with T2D, and has been associated with an increased risk of CVD and death $[93,94]$. Therefore, raising awareness of CKD risk factors amongst both people with diabetes and healthcare professionals in primary care is essential, as it is likely that individuals with T2D referred early to specialist nephrology services will have much better outcomes than those whose referral is delayed.
However, there are few studies examining risk factors for CKD in people with T2D. The few studies that have assessed CKD risk have identified albuminuria and eGFR as being the most important factors to predict onset and progression of early CKD in individuals with T2D $[95,96]$. We have summarised in a simple traffic light system the key risk factors that healthcare professionals working in primary care should be aware of in order to appropriately identify people with T2D at high, moderate and low risk of CKD (Fig. 3).

\section{Risk Factors Associated with High Risk of CKD in T2D}

It is well established that poor glycaemic control and elevated HbA1c is critical in the aetiology of CKD in people with T2D [97]. Ten years of an intensive glycaemic control intervention in people with newly diagnosed T2D resulted in a $24 \%$ reduction in development of microvascular complications, including CKD, compared with conventional dietary therapy [7]. 
Increased urinary albumin excretion is a major risk factor for CKD [98]. Whilst moderately increased urinary albumin excretion, i.e. $3-30 \mathrm{mg} / \mathrm{mmol}$ creatinine in a spot urine sample (microalbuminuria), is the first sign of CKD, people who develop severely increased albuminuria, i.e. more than $30 \mathrm{mg}$ albumin/mmol creatinine in a spot urine sample (macroalbuminuria), are at particularly high risk for developing a decline in renal function [99-101].

Acute kidney injury is common condition, affecting $20 \%$ of all emergency admissions [102], and is an important risk factor for the development of CKD. We suggest that there should be regular monitoring for the development or progression of CKD after an acute kidney injury, even if serum creatinine has returned to baseline.

Consensus expert opinion concluded that additional risk factors which place individuals with T2D at high risk of CKD include co-existing diabetic complications such as CVD or HF, and longer duration of T2D (more than 10 years). CKD is uncommon if T2D is less than one decade in duration, and there are no other risk factors for CKD. Individuals with a longer duration of diabetes have a higher risk for developing $\mathrm{CKD}$, with the highest incidence rates of $3 \%$ per year generally observed 10-20 years after diabetes onset, after which the rate of CKD tapers off $[103,104]$.

Our consensus view based on the above discussion is that the presence of one or more of these factors should alert to the presence of kidney disease.

\section{Risk Factors Associated with Moderate Risk of CKD in T2D}

There are a number of lifestyle factors that are associated with a moderate risk of CKD both in people with and without T2D. An unhealthy diet (e.g. an energy-dense Western style diet), physical inactivity and the associated obesity are well-established risk factors that can increase the risk of complications, such as CKD $[105,106]$. Smoking has also been associated with increased albuminuria as well as with a decline in GFR in people with T2D [107, 108].
Reducing or quitting smoking should be encouraged in people with $\mathrm{T} 2 \mathrm{D}$ in order to reduce the risk of CKD.

There is marked difference with regards to ethnicity in the epidemiology of CKD in people with and without T2D, with Native Americans, Hispanics and African-Americans having a greater risk of developing end stage kidney disease (ESKD) compared with non-Hispanic Whites [100, 109]. In addition, South Asians with T2D are more likely to develop diabetic complications such as CKD, compared with other ethnic groups [46].

Elevated blood pressure is another important independent risk factor for CKD; baseline systolic blood pressure greater than $140 \mathrm{mmHg}$ in people with T2D has been associated with higher risk of ESKD and death [110, 111].

It is well established that in people with diabetes, the presence of retinopathy (a deterioration of the blood vessels in the retina that can cause vision loss and blindness) is a predictor for other diabetes-related complications [112], and has previously been demonstrated to be a risk factor for progression of CKD in people with T2D [113, 114]. Routine follow-up in people with T2D with retinopathy is therefore important for both the management of retinopathy and to monitor renal function in these individuals, so as to prevent $\mathrm{CKD}$ progression.

On the basis of the above discussion, our consensus view is that the presence of two or more of these factors should act as an alert to the need to evaluate an individual for the presence of undiagnosed CKD.

\section{Risk Factors Associated with Low Risk of CKD in T2D}

Compared with the typical onset of T2D in middle age or older, T2D with early age of onset is associated with poorer metabolic control and a higher risk of diabetes-related complications such as CKD [115-117]. Individuals under 45 years with absence of any of the above risk factors should be considered to be at low risk of CKD. 


\section{SUMMARY}

Diabetes is a major health issue that continues to increase across the world [118], and which can lead to a number of short- and long-term health complications, including hyperglycaemia, heart disease, kidney disease, nerve damage, amputation and vision problems. True diabetes primary prevention would be to identify high-risk individuals when they are still in a normoglycemic state and to offer an intervention that prevents the transition from normoglycemia to impaired glucose tolerance and diabetes. NICE [21], European guidelines for the prevention of type 2 diabetes [119] and the International Diabetes Federation [120] recommend the use of prediction models to identify people at high risk of diabetes. However, despite there being numerous currently available risk assessment tools for diabetes the level of risk indicated by these tools can differ [23], and there is uncertainty in how best to identify high-risk individuals using the currently advocated risk assessments.

The guidance presented here provides a valuable reference for healthcare professionals contributing to diabetes treatment and care offering expert consensus advice regarding risk factors that can identify individuals at high, moderate and low risk of undiagnosed T2D, and T2D-related complications. Although increased awareness is a great starting point, it is not enough on its own. The risk predictors should be assessed on a continual basis for continued monitoring of risk and individuals identified as being at high risk of T2D or T2D complications should be screened for these conditions as appropriate. Furthermore, as many of the discussed risk predictors are modifiable, the introduction of appropriate interventions to reduce the risk will be essential for the prevention of diabetes and/or its complications.

It is important to note that unlike other published risk scores, the proposed traffic light system for identifying risk of undiagnosed T2D and T2D-related complications is not evidenced based and is not validated; the risk factors were included following consensus expert discussion. The purpose of this review is to increase awareness among non-specialists of the factors that put an individual at increased risk of undiagnosed T2D and T2D-related complications. The use of the proposed traffic light system should be the first step in evaluating risk. Further risk assessment, using a validated method, will be required to characterise an individual's true risk.

In conclusion, increased awareness of the key risk factors is likely to reduce the clinical and economic burden of diabetes through the detection of the 'missing million', and the application of prevention strategies in this population to avoid the onset of diabetic complications.

\section{ACKNOWLEDGEMENTS}

Funding. No funding was received for the study or publication of this article.

Authorship. All named authors meet the International Committee of Medical Journal Editors (ICMJE) criteria for authorship for this article, take responsibility for the integrity of the work as a whole, and have given their approval for this version to be published.

Disclosures. Philip Newland-Jones has received sponsorship, honoraria, or undertaken research for Abbott, AstraZeneca, Boehringer, Eli Lilly, Napp, Novonordisk and Sanofi. Zaheer Yousef has received honoraria from AstraZeneca, Boehringer Ingelheim, Novartis, Abbott, Lilly, Pfizer, Bristol Myers Squibb for attending and participating in educational events and advisory boards. Bethany Kelly has received sponsorship, honoraria, or undertaken work for AstraZeneca, Napp, Novonordisk, BD and Sanofi. Jim Moore declares the following conflicts of interest: President Primary Care Cardiovascular Society, Observer on the British Society for Heart Failure Board, Member of the National Heart Failure Audit Domain Expert Group, NICE Guideline Committee memberChronic Heart Failure 2018, and in the last year honoraria has been received from Amgen, AstraZeneca, Bayer, Boehringer Ingelheim and 
Novartis for various activities including attending and participating in educational events and advisory boards. Sarah Davies has received honorarium from AstraZeneca, Boehringer Ingelheim, Lilly, Novo Nordisk, Takeda, MSD, Napp, Bayer and Roche for attending and participating in educational events and advisory boards. Marc Evans is editor in chief of the journal. Angharad R. Morgan, Dipesh Patel, Ketan Dhatariya, Sharlene Greenwood, Debbie Hicks and Umesh Dashora have nothing to disclose.

Compliance with Ethics Guidelines. This article is based on previously conducted studies and does not contain any studies with human participants or animals performed by any of the authors.

Data Availability. Data sharing is not applicable to this article as no datasets were generated or analysed during the current study.

Open Access. This article is licensed under a Creative Commons Attribution-NonCommercial 4.0 International License, which permits any non-commercial use, sharing, adaptation, distribution and reproduction in any medium or format, as long as you give appropriate credit to the original author(s) and the source, provide a link to the Creative Commons licence, and indicate if changes were made. The images or other third party material in this article are included in the article's Creative Commons licence, unless indicated otherwise in a credit line to the material. If material is not included in the article's Creative Commons licence and your intended use is not permitted by statutory regulation or exceeds the permitted use, you will need to obtain permission directly from the copyright holder. To view a copy of this licence, visit http://creativecommons.org/licenses/by$\mathrm{nc} / 4.0 /$.

\section{REFERENCES}

1. Saeedi P, Petersohn I, Salpea P, et al. Global and regional diabetes prevalence estimates for 2019 and projections for 2030 and 2045: Results from the International Diabetes Federation Diabetes Atlas, 9(th) edition. Diabetes Res Clin Pract. 2019;157: 107843.

2. Beagley J, Guariguata L, Weil C, et al. Global estimates of undiagnosed diabetes in adults. Diabetes Res Clin Pract. 2014;103(2):150-60.

3. Diabetes UK. Missing million: perceptions and reality of diabetes today. 2000. https://www. diabetes.org.uk/about_us/news_landing_page/ 2000/missing-million-perceptions-and-reality-ofdiabetes-today.Accessed 11 Sept 2020.

4. Young K, Jones A, Thomas N, et al. HbA1c screening in 195,460 'non-diabetic' individuals (40-69 years) identifies $1.1 \%$ with undiagnosed diabetes 2 years before clinical diagnosis. Diabetologia. 2020;63(Suppl 1):S166.

5. Fry A, Littlejohns TJ, Sudlow C, et al. Comparison of sociodemographic and health-related characteristics of UK Biobank participants with those of the general population. Am J Epidemiol. 2017;186(9): 1026-34.

6. Genuth S, Eastman R, Kahn R, et al. Implications of the United Kingdom prospective diabetes study. Diabetes Care. 2003;26(Suppl 1):S28-32.

7. Holman RR, Paul SK, Bethel MA, et al. 10-year follow-up of intensive glucose control in type 2 diabetes. N Engl J Med. 2008;359(15):1577-89.

8. Gaede P, Lund-Andersen H, Parving HH, et al. Effect of a multifactorial intervention on mortality in type 2 diabetes. N Engl J Med. 2008;358(6):580-91.

9. Neal B, Perkovic V, Matthews DR. Canagliflozin and cardiovascular and renal events in type 2 diabetes. N Engl J Med. 2017;377(21):2099.

10. Wiviott SD, Raz I, Bonaca MP, et al. Dapagliflozin and cardiovascular outcomes in type 2 diabetes. N Engl J Med. 2019;380(4):347-57.

11. Zinman B, Wanner C, Lachin JM, et al. Empagliflozin, cardiovascular outcomes, and mortality in type 2 diabetes. N Engl J Med. 2015;373(22): 2117-28.

12. Perkovic V, Jardine MJ, Neal B, et al. Canagliflozin and renal outcomes in type 2 diabetes and nephropathy. N Engl J Med. 2019;380(24): 2295-306.

13. McMurray JJV, Solomon SD, Inzucchi SE, et al. Dapagliflozin in patients with heart failure and reduced ejection fraction. $\mathrm{N}$ Engl $\mathrm{J}$ Med. 2019;381(21):1995-2008. 
14. Cannon CP, McGuire DK, Pratley R, et al. Design and baseline characteristics of the eValuation of ERTugliflozin effIcacy and Safety CardioVascular outcomes trial (VERTIS-CV). Am Heart J. 2018;206: 11-23.

15. Engelgau MM, Narayan KM, Herman WH. Screening for type 2 diabetes. Diabetes Care. 2000;23(10): 1563-80.

16. The DECODE study group on behalf of the European Diabetes Epidemiology Group. Glucose tolerance and mortality: comparison of WHO and American Diabetes Association diagnostic criteria. Lancet. 1999;354(9179):617-21.

17. Wild SH, Smith FB, Lee AJ, et al. Criteria for previously undiagnosed diabetes and risk of mortality: 15-year follow-up of the Edinburgh Artery Study cohort. Diabet Med. 2005;22(4):490-6.

18. Valdés S, Botas P, Delgado E, et al. Mortality risk in Spanish adults with diagnosed diabetes, undiagnosed diabetes or pre-diabetes. The Asturias study 1998-2004. Rev Esp Cardiol. 2009;62(5):528-34.

19. Hex N, Bartlett C, Wright D, et al. Estimating the current and future costs of type 1 and type 2 diabetes in the UK, including direct health costs and indirect societal and productivity costs. Diabet Med. 2012;29(7):855-62.

20. Tseng E, Greer RC, O'Rourke P, et al. Survey of primary care providers' knowledge of screening for, diagnosing and managing prediabetes. J Gen Intern Med. 2017;32(11):1172-8.

21. National Institute for Health and Care Excellence. PH38: Preventing type 2 diabetes: risk identification and interventions for individuals at high risk. 2012. https://www.nice.org.uk/guidance/ph38.Accessed 11 Sept 2020.

22. Dhatariya KK, Glaser NS, Codner E, et al. Diabetic ketoacidosis. Nat Rev Dis Primers. 2020;6(1):40.

23. Gray BJ, Bracken RM, Turner D, et al. Different type 2 diabetes risk assessments predict dissimilar numbers at 'high risk': a retrospective analysis of diabetes risk-assessment tools. $\mathrm{Br} \mathrm{J}$ Gen Pract. 2015;65(641):e852-60.

24. Buijsse B, Simmons RK, Griffin SJ, et al. Risk assessment tools for identifying individuals at risk of developing type 2 diabetes. Epidemiol Rev. 2011;33(1):46-62.

25. World Health Organization. Definition and diagnosis of diabetes mellitus and intermediate hyperglycaemia: report of a WHO/IDF consultation. 2006. https://www.who.int/diabetes/publications/ diagnosis_diabetes2006/en/. Accessed 11 Sept 2020.
26. Knowler WC, Barrett-Connor E, Fowler SE, et al. Reduction in the incidence of type 2 diabetes with lifestyle intervention or metformin. N Engl J Med. 2002;346(6):393-403.

27. Lindström J, Eriksson JG, Valle TT, et al. Prevention of diabetes mellitus in subjects with impaired glucose tolerance in the Finnish Diabetes Prevention Study: results from a randomized clinical trial. J Am Soc Nephrol. 2003;14(7 Suppl 2):S108-13.

28. Pan XR, Li GW, Hu YH, et al. Effects of diet and exercise in preventing NIDDM in people with impaired glucose tolerance. The Da Qing IGT and Diabetes Study. Diabetes Care. 1997;20(4):537-44.

29. Ramachandran A, Snehalatha C, Mary S, et al. The Indian Diabetes Prevention Programme shows that lifestyle modification and metformin prevent type 2 diabetes in Asian Indian subjects with impaired glucose tolerance (IDPP-1). Diabetologia. 2006;49(2):289-97.

30. Tabák AG, Herder C, Rathmann W, et al. Prediabetes: a high-risk state for diabetes development. Lancet. 2012;379(9833):2279-90.

31. Kim SM, Lee G, Choi S, et al. Association of earlyonset diabetes, prediabetes and early glycaemic recovery with the risk of all-cause and cardiovascular mortality. Diabetologia. 2020;63(11):2305-14.

32. American Diabetes Association. 2. Classification and diagnosis of diabetes: standards of medical care in diabetes-2019. Diabetes Care. 2019;42(Suppl 1): S13-s28.

33. Bellamy L, Casas JP, Hingorani AD, et al. Type 2 diabetes mellitus after gestational diabetes: a systematic review and meta-analysis. Lancet. 2009;373(9677):1773-9.

34. Vounzoulaki E, Khunti K, Abner SC, et al. Progression to type 2 diabetes in women with a known history of gestational diabetes: systematic review and meta-analysis. BMJ. 2020;369:m1361.

35. Geer EB, Islam J, Buettner C. Mechanisms of glucocorticoid-induced insulin resistance: focus on adipose tissue function and lipid metabolism. Endocrinol Metab Clin N Am. 2014;43(1):75-102.

36. Liu XX, Zhu XM, Miao Q, et al. Hyperglycemia induced by glucocorticoids in nondiabetic patients: a meta-analysis. Ann Nutr Metab. 2014;65(4):324-32.

37. Clore JN, Thurby-Hay L. Glucocorticoid-induced hyperglycemia. Endocr Pract. 2009;15(5):469-74.

38. Gurwitz JH, Bohn RL, Glynn RJ, et al. Glucocorticoids and the risk for initiation of hypoglycemic therapy. Arch Intern Med. 1994;154(1):97-101. 
39. Buddeke J, Bots ML, van Dis I, et al. Comorbidity in patients with cardiovascular disease in primary care: a cohort study with routine healthcare data. $\mathrm{Br} \mathrm{J}$ Gen Pract. 2019;69(683):e398-406.

40. World Health Organization. Global status report on noncommunicable diseases. 2014. https://www. who.int/nmh/publications/ncd-status-report-2014/ en/. Accessed 11 Sept 2020.

41. Goff LM. Ethnicity and type 2 diabetes in the UK. Diabet Med. 2019;36(8):927-38.

42. Centres for Disease Control and Prevention. National Diabetes Statistics Report 2020: estimates of diabetes and its burden in the United States. 2020. https://www.cdc.gov/diabetes/pdfs/data/ statistics/national-diabetes-statistics-report.pdf.Accessed 11 Sept 2020.

43. Paul SK, Owusu Adjah ES, Samanta M, et al. Comparison of body mass index at diagnosis of diabetes in a multi-ethnic population: a case-control study with matched non-diabetic controls. Diabetes Obes Metab. 2017;19(7):1014-23.

44. Pham TM, Carpenter JR, Morris TP, et al. Ethnic differences in the prevalence of type 2 diabetes diagnoses in the UK: cross-sectional analysis of the health improvement network primary care database. Clin Epidemiol. 2019;11:1081-8.

45. Winkley K, Thomas SM, Sivaprasad S, et al. The clinical characteristics at diagnosis of type 2 diabetes in a multi-ethnic population: the South London Diabetes cohort (SOUL-D). Diabetologia. 2013;56(6):1272-81.

46. Hills AP, Arena R, Khunti K, et al. Epidemiology and determinants of type 2 diabetes in south Asia. Lancet Diabetes Endocrinol. 2018;6(12):966-78.

47. Diabetes UK. Diabetes Facts and Stats. 2014. https:// www.diabetes.org.uk/Documents/About\%20Us/ Statistics/Diabetes-key-stats-guidelines-April2014. pdf.Accessed 11 Sept 2020.

48. Schnurr TM, Jakupović H, Carrasquilla GD, et al. Obesity, unfavourable lifestyle and genetic risk of type 2 diabetes: a case-cohort study. Diabetologia. 2020;63(7):1324-32.

49. National Institute for Health and Care Excellence. PH35. Preventing type 2 diabetes: population and community-level interventions. 2011. https://www. nice.org.uk/guidance/ph35.Accessed 11 Sept 2020.

50. Schienkiewitz A, Schulze MB, Hoffmann K, et al. Body mass index history and risk of type 2 diabetes: results from the European Prospective Investigation into Cancer and Nutrition (EPIC)-Potsdam Study. Am J Clin Nutr. 2006;84(2):427-33.
51. American Diabetes Association. 2. Classification and diagnosis of diabetes: standards of medical care in diabetes-2020. Diabetes Care. 2020;43(Suppl 1): S14-s31.

52. Liu X, Bragg F, Yang L, et al. Smoking and smoking cessation in relation to risk of diabetes in Chinese men and women: a 9-year prospective study of 0.5 million people. Lancet Public Health. 2018;3(4): e167-76.

53. Pan A, Wang Y, Talaei M, et al. Relation of active, passive, and quitting smoking with incident type 2 diabetes: a systematic review and meta-analysis. Lancet Diabetes Endocrinol. 2015;3(12):958-67.

54. Willi C, Bodenmann P, Ghali WA, et al. Active smoking and the risk of type 2 diabetes: a systematic review and meta-analysis. JAMA. 2007;298(22): 2654-64.

55. Papazafiropoulou AK, Papanas N, Melidonis A, et al. Family history of type 2 diabetes: does having a diabetic parent increase the risk? Curr Diabetes Rev. 2017;13(1):19-25.

56. Emdin CA, Anderson SG, Woodward M, et al. Usual blood pressure and risk of new-onset diabetes: evidence from 4.1 million adults and a meta-analysis of prospective studies. J Am Coll Cardiol. 2015;66(14):1552-62.

57. Rotterdam ESHRE/ASRM-Sponsored PCOS Consensus Workshop Group. Revised 2003 consensus on diagnostic criteria and long-term health risks related to polycystic ovary syndrome. Fertil Steril. 2004;81(1):19-25.

58. Legro RS, Arslanian SA, Ehrmann DA, et al. Diagnosis and treatment of polycystic ovary syndrome: an Endocrine Society clinical practice guideline. J Clin Endocrinol Metab. 2013;98(12):4565-92.

59. Rubin KH, Glintborg D, Nybo M, et al. Development and risk factors of type 2 diabetes in a nationwide population of women with polycystic ovary syndrome. J Clin Endocrinol Metab. 2017;102(10):3848-57.

60. Mani H, Levy MJ, Davies MJ, et al. Diabetes and cardiovascular events in women with polycystic ovary syndrome: a 20-year retrospective cohort study. Clin Endocrinol (Oxf). 2013;78(6):926-34.

61. Perumpail BJ, Khan MA, Yoo ER, et al. Clinical epidemiology and disease burden of nonalcoholic fatty liver disease. World J Gastroenterol. 2017;23(47):8263-76.

62. Bedossa P. Pathology of non-alcoholic fatty liver disease. Liver Int. 2017;37(Suppl 1):85-9. 
63. Dyson JK, Anstee QM, McPherson S. Non-alcoholic fatty liver disease: a practical approach to diagnosis and staging. Frontline Gastroenterol. 2014;5(3): 211-8.

64. Younossi ZM, Golabi P, de Avila L, et al. The global epidemiology of NAFLD and NASH in patients with type 2 diabetes: a systematic review and metaanalysis. J Hepatol. 2019;71(4):793-801.

65. Mantovani A, Byrne CD, Bonora E, et al. Nonalcoholic fatty liver disease and risk of incident type 2 diabetes: a meta-analysis. Diabetes Care. 2018;41(2): 372-82.

66. NHS Digital. National Diabetes Audit - 2012-2013: Report 1, Care Processes and Treatment Targets. 2014. https://digital.nhs.uk/data-and-information/ publications/statistical/national-diabetes-audit/ national-diabetes-audit-2012-2013-report-1-careprocesses-and-treatment-targets.Accessed $11 \mathrm{Sept}$ 2020.

67. Kannel WB, Hjortland M, Castelli WP. Role of diabetes in congestive heart failure: the Framingham study. Am J Cardiol. 1974;34(1):29-34.

68. Kannel WB, McGee DL. Diabetes and cardiovascular disease. The Framingham study. JAMA. 1979;241(19):2035-8.

69. Echouffo-Tcheugui JB, Xu H, DeVore AD, et al. Temporal trends and factors associated with diabetes mellitus among patients hospitalized with heart failure: findings from Get With The Guidelines-Heart Failure registry. Am Heart J. 2016;182: 9-20.

70. Bertoni AG, Hundley WG, Massing MW, et al. Heart failure prevalence, incidence, and mortality in the elderly with diabetes. Diabetes Care. 2004;27(3): 699-703.

71. Carr AA, Kowey PR, Devereux RB, et al. Hospitalizations for new heart failure among subjects with diabetes mellitus in the RENAAL and LIFE studies. Am J Cardiol. 2005;96(11):1530-6.

72. Segar MW, Vaduganathan M, Patel KV, et al. Machine learning to predict the risk of incident heart failure hospitalization among patients with diabetes: the WATCH-DM risk score. Diabetes Care. 2019;42(12):2298-306.

73. Berg DD, Wiviott SD, Scirica BM, et al. Heart failure risk stratification and efficacy of sodium-glucose cotransporter-2 inhibitors in patients with type 2 diabetes mellitus. Circulation. 2019;140(19): 1569-77.

74. Basset A, Nowak E, Castellant P, et al. Development of a clinical prediction score for congestive heart failure diagnosis in the emergency care setting: the Brest score. Am J Emerg Med. 2016;34(12):2277-83.

75. Ponikowski P, Voors AA, Anker SD, et al. 2016 ESC Guidelines for the diagnosis and treatment of acute and chronic heart failure: the task force for the diagnosis and treatment of acute and chronic heart failure of the European Society of Cardiology (ESC) developed with the special contribution of the Heart Failure Association (HFA) of the ESC. Eur Heart J. 2016;37(27):2129-200.

76. Roger VL. Epidemiology of heart failure. Circ Res. 2013;113(6):646-59.

77. Zareini B, Rorth R, Holt A, et al. Heart failure and the prognostic impact and incidence of new-onset of diabetes mellitus: a nationwide cohort study. Cardiovasc Diabetol. 2019;18(1):79.

78. National Institute for Health and Care Excellence. NICE guideline [NG106]: Chronic heart failure in adults: diagnosis and management. 2018. https:// www.nice.org.uk/guidance/ng106.Accessed 11 Sept 2020.

79. O’Neal WT, Mazur M, Bertoni AG, et al. Electrocardiographic predictors of heart failure with reduced versus preserved ejection fraction: the multi-ethnic study of atherosclerosis. J Am Heart Assoc. 2017;6(6):e006023.

80. Huo X, Gao L, Guo L, et al. Risk of non-fatal cardiovascular diseases in early-onset versus late-onset type 2 diabetes in China: a cross-sectional study. Lancet Diabetes Endocrinol. 2016;4(2):115-24.

81. Damman K, Valente MA, Voors AA, et al. Renal impairment, worsening renal function, and outcome in patients with heart failure: an updated meta-analysis. Eur Heart J. 2014;35(7):455-69.

82. Wang Y, Katzmarzyk PT, Horswell R, et al. Comparison of the heart failure risk stratification performance of the CKD-EPI equation and the MDRD equation for estimated glomerular filtration rate in patients with type 2 diabetes. Diabet Med. 2016;33(5):609-20.

83. Gerstein HC, Mann JF, Pogue J, et al. Prevalence and determinants of microalbuminuria in high-risk diabetic and nondiabetic patients in the Heart Outcomes Prevention Evaluation Study. The HOPE Study Investigators. Diabetes Care. 2000;23(Suppl 2):B35-9.

84. Gerstein HC, Mann JF, Yi Q, et al. Albuminuria and risk of cardiovascular events, death, and heart failure in diabetic and nondiabetic individuals. JAMA. 2001;286(4):421-6. 
85. Kenchaiah S, Chesebro JH. The epidemiologic association between obesity and heart failure. Am Coll Cardiol Ext Learn. 2017;49(8):4-6.

86. Kenchaiah S, Sesso HD, Gaziano JM. Body mass index and vigorous physical activity and the risk of heart failure among men. Circulation. 2009;119(1): 44-52.

87. Slivnick J, Lampert BC. Hypertension and heart failure. Heart Fail Clin. 2019;15(4):531-41.

88. Hypertension in Diabetes Study (HDS). I. Pevalence of hypertension in newly presenting type 2 diabetic patients and the association with risk factors for cardiovascular and diabetic complications. J Hypertens. 1993;11(3):309-17.

89. Aune D, Schlesinger S, Norat $T$, et al. Tobacco smoking and the risk of heart failure: a systematic review and meta-analysis of prospective studies. Eur J Prev Cardiol. 2019;26(3):279-88.

90. Lee H, Son YJ. Influence of smoking status on risk of incident heart failure: a systematic review and meta-analysis of prospective cohort studies. Int $\mathrm{J}$ Environ Res Public Health. 2019;16(15):2697.

91. Gheith O, Farouk N, Nampoory N, et al. Diabetic kidney disease: world wide difference of prevalence and risk factors. J Nephropharmacol. 2016;5(1): 49-56.

92. Bailey RA, Wang Y, Zhu V, et al. Chronic kidney disease in US adults with type 2 diabetes: an updated national estimate of prevalence based on Kidney Disease: Improving Global Outcomes (KDIGO) staging. BMC Res Notes. 2014;7:415.

93. Narres M, Claessen H, Droste S, et al. The incidence of end-stage renal disease in the diabetic (compared to the non-diabetic) population: a systematic review. PLoS One. 2016;11(1):e0147329.

94. Nichols GA, Déruaz-Luyet A, Hauske SJ, et al. The association between estimated glomerular filtration rate, albuminuria, and risk of cardiovascular hospitalizations and all-cause mortality among patients with type 2 diabetes. J Diabetes Complications. 2018;32(3):291-7.

95. Dunkler D, Gao P, Lee SF, et al. Risk prediction for early CKD in type 2 diabetes. Clin J Am Soc Nephrol. 2015;10(8):1371-9.

96. Ninomiya T, Perkovic V, de Galan BE, et al. Albuminuria and kidney function independently predict cardiovascular and renal outcomes in diabetes. J Am Soc Nephrol. 2009;20(8):1813-21.
97. MacIsaac RJ, Jerums G, Ekinci EI. Effects of glycaemic management on diabetic kidney disease. World J Diabetes. 2017;8(5):172-86.

98. Gall MA, Hougaard P, Borch-Johnsen K, et al. Risk factors for development of incipient and overt diabetic nephropathy in patients with non-insulin dependent diabetes mellitus: prospective, observational study. BMJ. 1997;314(7083):783-8.

99. KDOQI. KDOQI clinical practice guidelines and clinical practice recommendations for diabetes and chronic kidney disease. Am J Kidney Dis. 2007;49(2 Suppl 2):S12-154.

100. de Boer IH, Afkarian M, Rue TC, et al. Renal outcomes in patients with type 1 diabetes and macroalbuminuria. J Am Soc Nephrol. 2014;25(10): 2342-50.

101. Molitch ME, Steffes M, Sun W, et al. Development and progression of renal insufficiency with and without albuminuria in adults with type 1 diabetes in the diabetes control and complications trial and the epidemiology of diabetes interventions and complications study. Diabetes Care. 2010;33(7): 1536-43.

102. Challiner R, Ritchie JP, Fullwood C, et al. Incidence and consequence of acute kidney injury in unselected emergency admissions to a large acute UK hospital trust. BMC Nephrol. 2014;15:84.

103. Batuman V, Schmidt RJ, Soman AS, et al. Diabetic nephropathy. 2019. https://emedicine.medscape. com/article/238946-overview\#a5.Accessed 11 Sept 2020.

104. Cederholm J, Eliasson B, Nilsson PM, et al. Microalbuminuria and risk factors in type 1 and type 2 diabetic patients. Diabetes Res Clin Pract. 2005;67(3):258-66.

105. Roberts CK, Barnard RJ. Effects of exercise and diet on chronic disease. J Appl Physiol (1985). 2005;98(1):3-30.

106. Ejerblad E, Fored CM, Lindblad P, et al. Obesity and risk for chronic renal failure. J Am Soc Nephrol. 2006;17(6):1695-702.

107. Gambaro G, Bax G, Fusaro M, et al. Cigarette smoking is a risk factor for nephropathy and its progression in type 2 diabetes mellitus. Diabetes Nutr Metab. 2001;14(6):337-42.

108. Liao D, Ma L, Liu J, et al. Cigarette smoking as a risk factor for diabetic nephropathy: a systematic review and meta-analysis of prospective cohort studies. PLoS One. 2019;14(2):e0210213. 
109. de Boer IH. Kidney disease and related findings in the diabetes control and complications trial/epidemiology of diabetes interventions and complications study. Diabetes Care. 2014;37(1):24-30.

110. Bakris GL, Weir MR, Shanifar S, et al. Effects of blood pressure level on progression of diabetic nephropathy: results from the RENAAL study. Arch Intern Med. 2003;163(13):1555-65.

111. Pohl MA, Blumenthal S, Cordonnier DJ, et al. Independent and additive impact of blood pressure control and angiotensin II receptor blockade on renal outcomes in the irbesartan diabetic nephropathy trial: clinical implications and limitations. J Am Soc Nephrol. 2005;16(10):3027-37.

112. El-Asrar AM, Al-Rubeaan KA, Al-Amro SA, et al. Retinopathy as a predictor of other diabetic complications. Int Ophthalmol. 2001;24(1):1-11.

113. Park HC, Lee YK, Cho A, et al. Diabetic retinopathy is a prognostic factor for progression of chronic kidney disease in the patients with type 2 diabetes mellitus. PLoS One. 2019;14(7):e0220506.

114. Lin HT, Zheng CM, Wu YC, et al. Diabetic retinopathy as a risk factor for chronic kidney disease progression: a multicenter case-control study in Taiwan. Nutrients. 2019;11(3):509.

115. Pavkov ME, Bennett PH, Knowler WC, et al. Effect of youth-onset type 2 diabetes mellitus on incidence of end-stage renal disease and mortality in young and middle-aged Pima Indians. JAMA. 2006;296(4):421-6.

116. Wong J, Molyneaux L, Constantino M, et al. Timing is everything: age of onset influences long-term retinopathy risk in type 2 diabetes, independent of traditional risk factors. Diabetes Care. 2008;31(10): 1985-90.

117. Li L, Ji L, Guo X, et al. Prevalence of microvascular diseases among tertiary care Chinese with early versus late onset of type 2 diabetes. J Diabetes Complications. 2015;29(1):32-7.

118. International Diabetes Federation. IDF Diabetes Atlas, 9th edn. 2019. https://www.diabetesatlas.org. Accessed 11 Sept 2020.

119. Paulweber B, Valensi P, Lindström J, et al. A European evidence-based guideline for the prevention of type 2 diabetes. Horm Metab Res. 2010;42(Suppl 1): S3-36.
120. Alberti KG, Zimmet P, Shaw J. International Diabetes Federation: a consensus on type 2 diabetes prevention. Diabet Med. 2007;24(5):451-63.

121. Diabetes UK. Type 2 diabetes. Know your risk. 2020. https://riskscore.diabetes.org.uk.Accessed 11 Sept 2020.

122. Griffin SJ, Little PS, Hales CN, et al. Diabetes risk score: towards earlier detection of type 2 diabetes in general practice. Diabetes Metab Res Rev. 2000;16(3):164-71.

123. Gray LJ, Taub NA, Khunti K, et al. The Leicester Risk Assessment score for detecting undiagnosed type 2 diabetes and impaired glucose regulation for use in a multiethnic UK setting. Diabet Med. 2010;27(8): 887-95.

124. Hippisley-Cox J, Coupland C, Robson J, et al. Predicting risk of type 2 diabetes in England and Wales: prospective derivation and validation of QDScore. BMJ. 2009;338:b880.

125. Lindström J, Tuomilehto J. The diabetes risk score: a practical tool to predict type 2 diabetes risk. Diabetes Care. 2003;26(3):725-31.

126. Glümer C, Carstensen B, Sandbaek A, et al. A Danish diabetes risk score for targeted screening: the Inter99 study. Diabetes Care. 2004;27(3):727-33.

127. Balkau B, Lange C, Fezeu L, et al. Predicting diabetes: clinical, biological, and genetic approaches: data from the Epidemiological Study on the Insulin Resistance Syndrome (DESIR). Diabetes Care. 2008;31(10):2056-61.

128. Schulze MB, Hoffmann $\mathrm{K}$, Boeing $\mathrm{H}$, et al. An accurate risk score based on anthropometric, dietary, and lifestyle factors to predict the development of type 2 diabetes. Diabetes Care. 2007;30(3):510-5.

129. American Diabetes Association. 2. Classification and diagnosis of diabetes. Diabetes Care. 2017;40(Suppl 1):S11-24.

130. Schmidt MI, Duncan BB, Bang H, et al. Identifying individuals at high risk for diabetes: the Atherosclerosis Risk in Communities study. Diabetes Care. 2005;28(8):2013-8.

131. Wilson PW, Meigs JB, Sullivan L, et al. Prediction of incident diabetes mellitus in middle-aged adults: the Framingham Offspring Study. Arch Intern Med. 2007;167(10):1068-74. 